\title{
Frequency and clinical significance of urinary schistosomiasis in haemophilia
}

Umma A Ibrahim, Sagir G Ahmed, Modu B Kagu, Usman A Abjah

Haematuria is not uncommon in people with haemophilia and is mainly caused by spontaneous haemorrhage or trauma. The frequency and clinical significance of urinary schistosomiasis in the aetiology of haematuria among haemophiliacs in schistosomiasis endemic countries such as Nigeria have not been previously studied. We retrospectively analysed the clinical and laboratory data of 45 haemophiliacs with haematuria in Nigeria with the aim of determining the frequency of urinary schistosomiasis and other causes of haematuria among haemophiliacs, the haematological profiles of haemophiliacs with haematuria and the severity of schistosomal haematuria relative to non-schistosomal haematuria. Haematuria was due to spontaneous haemorrhage in $23(51.1 \%)$ patients, trauma in $14(31.1 \%)$ patients and schistosomiasis in 8 (17.8\%) patients. There were no significant differences in mean values of haematological parameters between patients with spontaneous and traumatic haematuria. However, compared to patients with spontaneous and traumatic haematuria, patients with schistosomal haematuria had significantly lower mean $\mathrm{Hb}$ concentration (8.5 vs.11 and $11.5 \mathrm{~g} / \mathrm{dL} ; \mathrm{p}<0.05$ ) and significantly higher mean eosinophil count $\left(0.42\right.$ vs. 0.21 and $\left.0.2 \times 10^{9} / \mathrm{L} ; \mathrm{p}<0.05\right)$. This study revealed that schistosomiasis was responsible for $17.8 \%$ of cases of haematuria in northern Nigerian haemophiliacs. Schistosomal haematuria was severe and caused significant anaemia in contradistinction to spontaneous and traumatic haematuria that were mild and did not cause significant anaemia. A superimposed pro-haemorrhagic host-parasite relationship was responsible for the severe haematuria seen in haemophiliacs with schistosomiasis, a situation that would potential increase their risk of iron deficiency and its attendant consequences including childhood cognitive impairment. Haemophiliacs with haematuria in schistosomiasis endemic countries should be investigated by urinalysis for early detection and treatment. Haemophiliacs who present with haematuria in association with eosinophilia should evoke the

Umma A. Ibrahim, Department of Paediatrics, Aminu Kano Teaching Hospital

PMB 3452, Kano, Kano State, Nigeria

Sagir G. Ahmed, Department of Haematology, Aminu Kano Teaching Hospital, PMB 3452, Kano, Kano State, Nigeria

Email: drsagirahmed@yahoo.com

Modu B. Kagu, Department of Haematology, University of Maiduguri Teaching Hospital, PMB 1414, Maiduguri, Borno State, Nigeria Usman A. Abjah, Department of Haematology, University of Maiduguri Teaching Hospital, PMB 1414, Maiduguri, Borno State, Nigeria

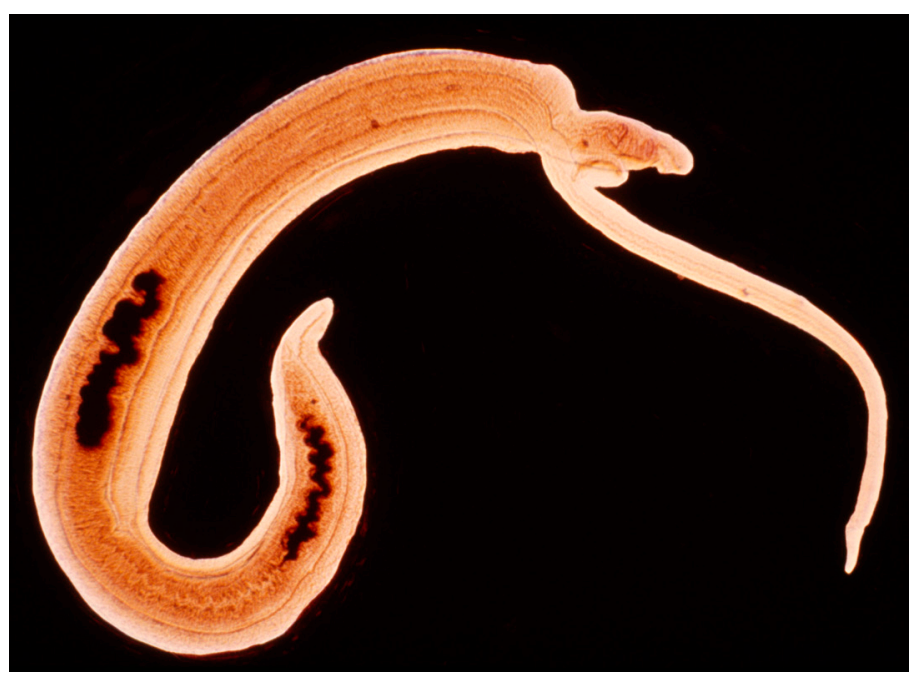

Wellcome Library, London

Figure 1: A pair of Schistosoma haematobium blood worms. The male (on the left) is broad; the longer and more slender female is on the right

strongest clinical suspicion for schistosomiasis. Parents of haemophiliacs should be counseled on how to protect their children from exposures to infected waters.

Keywords: haemophilia, haematuria, schistosomiasis, Nigeria

Haemophilia-A (HA) is an X-linked recessive disorder characterized by the deficiency of functional clotting factor VIII (FVIII), insufficient thrombin generation and lifelong bleeding diathesis. Residual FVIII levels determine the clinical severity of $\mathrm{HA}$, which is categorised as severe (FVIII level $<1 \%$ ), moderate (FVIII level $1-5 \%$ ) or mild (FVIII level 6-40\%) [1]. Haematuria is not uncommon in $\mathrm{HA}$ and is more frequent in patients with severe disease [2]. Bleeding can occur anywhere along the urinary tract, however, kidneys and bladder are the usual sources of haematuria in HA [2]. Most incidences of haematuria in children with HA occur spontaneously, however, in some cases haematuria may be associated with mild blunt abdominal trauma or urolithiasis [2,3]. Moreover, prostatic hyperplasia, urinary tract neoplasia and vigorous sexual intercourse may sometimes cause haematuria in adult patients with haemophilia [4]. To the best of our knowledge there is no report in the literature on the incidence, role and clinical significance of urinary schistosomiasis in the aetiology of haematuria in haemophilia patients. This may be due to the 
fact that most of the literature on haemophilia originated from non-tropical countries where urinary schistosomiasis is not prevalent. However, urinary schistosomiasis, which is caused by the parasite Schistosoma haematobium, is endemic in poor tropical countries, including Nigeria, where it is associated with a significant socioeconomic and public health burden especially in children [5].

In Nigeria, urinary schistosomiasis affects various categories of persons ranging from apparently healthy individuals to persons with background immunosuppressive conditions such as sickle cell disease [6-8]. The endemicity of urinary schistosomiasis in Nigeria is spatially distributed and is partly determined by ecological factors based on availability of surface waters. Hence, previous studies revealed that prevalence figures for urinary schistosomiasis in Nigeria range from $24.3 \%$ in the semi-desert northern region to as high as $62.0 \%$ in rain forest areas of the southern region $[7,8]$. Moreover, a previous report showed that urinary schistosomiasis was the predominant cause of haematuria in Nigerian children [9].

Nigerian children with haemophilia are as vulnerable to schistosomiasis as any person living in the same highrisk environment. We therefore expect that urinary schistosomiasis would be an important cause of haematuria in Nigerian children with haemophilia. Hence, in this study we retrospectively analysed the clinical and laboratory data of haemophilia patients who presented with haematuria in some hospitals in northern Nigeria with the aim of determining:

- the frequency of urinary schistosomiasis and other causes of haematuria among haemophilia patients;

- the haematological profiles of haemophilia patients with haematuria;

- the severity of schistosomal haematuria relative to nonschistosomal haematuria as reflected in the values of patients' haematological profiles.

Our findings are discussed in the light of the clinical significance of a haemostatically unbalanced host-parasite relationship between $S$. haematobium parasite and the haemophilic host.

\section{Materials and methods}

This is a retrospective study of data accrued from consecutive HA patients who presented with frankly macroscopic haematuria during an aggregate period of 27 years at

Table 1: Types of abdominal trauma among 14 haemophilia patients with traumatic haematuria

\begin{tabular}{|l|l|}
\hline Types of trauma & Number of patients (\%) \\
\hline Blunt trauma to the loin & $6(42.9)$ \\
\hline Blunt trauma to the flank & $5(35.7)$ \\
\hline Blunt trauma to the suprapubic area & $3(21.4)$ \\
\hline
\end{tabular}

different time periods in five Nigerian tertiary hospitals including University of Maiduguri Teaching Hospital, Maiduguri, northeast Nigeria (1996-2007), State Specialist Hospital, Maiduguri, northeast Nigeria (1996- 1999), Federal Medical Centre Birnin Kudu, northwest Nigeria (2004-2008), Murtala Muhammad Specialist Hospital, Kano, northwest Nigeria (2008-2010), and Aminu Kano Teaching Hospital, Kano, northwest Nigeria (2007-2009) The retrospectively accrued data collected from the five hospitals were collated and subjected to statistical analysis.

All the patients studied in this report were known cases of $\mathrm{HA}$ who were previously diagnosed on the basis of clotting profiles characterised by normal platelet count and bleeding time, normal prothrombin and thrombin times with prolonged activated partial thromboplastin time (APTT) corrected by mixing patient plasma with fresh normal plasma but not with aged plasma or serum [10]. The diagnoses were confirmed by FVIII assays performed by automated coagulometers or by manual techniques based on the ability of serial dilutions of patients plasma and standard plasma to correct the prolonged APTT of a plasma known to be severely deficient in FVIII [10]. Patients were categorised as severe (FVIII level $<1 \%$ ), moderate (FVIII level 1-5\%) or mild (FVIII level 6-40\%) haemophiliacs [10].

\section{Investigative procedures for haematuria}

All patients with HA who presented with haematuria at the five hospitals during the study were subjected to clinical history taking and examination, radiological and ultrasound evaluations of the abdomen, and microbiological urinalyses for detection of common parasitic and bacterial infections in accordance with local guidelines for routine investigations of haematuria [11]. The haematological parameters of each patient were determined as full blood counts using automated blood counters. These investigative procedures were carefully carried out to elicit any relevant history of blunt abdominal trauma and demonstrate or rule out other possible causes of haematuria such as tumors, stones, tissue damage or parasitic/bacterial infections within the urinary tract. The definitive causes of haematuria were determined on the basis of the findings of the investigative procedures.

\section{Ethical considerations and data collection}

This study was conducted with the approval of local institutional ethics committees. All research procedures were conducted with informed consents obtained from parents or guardians of young patients coupled with supplementary assent from older patients. We retrospectively collected the demographic profile (age and sex), FVIII levels and the definitive causes of haematuria in each patient as determined by investigative procedures described above and as documented in the laboratory and medical records of each patient.

\section{Statistical Analysis}

Data were collected from all five hospitals and collated. 
Comparative analyses of mean values were conducted using the t-test with $p$-values of less than 0.05 taken as significant.

\section{Results}

During the periods under review, a total of 41 male patients with severe $H A, 3$ with moderate $H A$ and 1 with mild $H A$ presented with frankly macroscopic haematuria at the five centres of study. Based on the results of the investigative procedures for haematuria, three main aetiological groups of haematuria were identified: spontaneous haemorrhage in $23(51.1 \%)$ patients, trauma in $14(31.1 \%)$ patients and schistosomiasis in $8(17.8 \%)$ patients. All cases of traumatic haematuria were due to mild blunt abdominal trauma, the pattern of which is shown in Table 1 . The distribution of severity of haemophilia among patients in the three aetiological groups of haematuria is shown on Table 2. The ages and haematological profiles of patients in the three aetiological groups of haematuria are shown in Table 3.

All patients with spontaneous and traumatic haematuria had severe haemophilia. However, 4 of the 8 patients with schistosomal haematuria had non-severe haemophilia (Table 2). There were no statistically significant differences in mean ages between patients in the three aetiological groups of haematuria $(p>0.05)$. There were also no statistically significant differences in mean values of all haematological parameters between patients with spontaneous and traumatic haematuria ( $p>0.05)$. However, compared to patients with spontaneous and traumatic haematuria, patients with schistosomal haematuria had significantly lower mean values of $\mathrm{Hb}$ concentration $(8.5$ vs.11 and $11.5 \mathrm{~g} / \mathrm{dL} ; \mathrm{p}<0.05)$ and haematocrit ( 0.25 vs. 0.33 and $0.34 \mathrm{l} / \mathrm{L} ; \mathrm{p}<0.05)$ and significantly higher mean values of eosinophil count ( 0.42 vs. 0.21 and $0.2 \times 10^{9} / \mathrm{L} ; \mathrm{p}<0.05$ ) and platelet count (466 vs. 226 and $237 \times 10^{9} / \mathrm{L} ; \mathrm{p}<0.05$ ). Up to $75 \%$ of patients with schistosomal haematuria had eosinophilia, while eosinophilia was not seen in patients with spontaneous or traumatic haematuria.

\section{Discussion}

The number of haemophilia patients captured in this study is relatively small despite a fairly extended period of multicentre data collection in a country such as Nigeria, which is the most populous country in Africa. This situation is related to poor access to tertiary medical care by the haemophilia patients coupled with the high mortality associated with the disease within a low resource medical care settings of a tropical country such as Nigeria. We believe that most haemophilia patients in Nigeria would have succumbed to their disease at sub-tertiary health institutions or in the hands of traditional healers in the rural areas before they could ever access tertiary health institutions that are almost exclusively located within the urban areas. Hence, the relatively small sample size of this study is only a reflection of the minority of haemophilia patients who were able to access tertiary health care in northern Nigeria. We acknowledge that the small sample size, as well as the retrospective nature of this study, are important limitations. Despite the limitations, the result of this study has identified three important, aetiological groups of haematuria among northern Nigerian haemophiliacs. Spontaneous haemorrhage and mild blunt abdominal trauma were the predominant causes of haematuria in this study, a pattern that is consistent with previous reports $[2,12]$. The frequency of schistosomiasis in our patients with haematuria was nearly 1 in 5 presentations with haematuria. We have also demonstrated that it is easily discernible by full blood count estimation to detect anaemia in the presence of an eosinophilia. Although the $17.8 \%$ detection rate in the haemophilia population is lower than the schistosomiasis prevalence rate of $24.3 \%$ previously reported in general population of north eastern Nigeria [7], clinicians in schistosomiasis-endemic regions should continue to be vigilant for schistosomiasis as a cause of haematuria and this study has confirmed our expectation that urinary schistosomiasis would be an important cause of haematuria among haemophiliacs in Nigeria.

The proportion of patients with severe haemophilia was unevenly distributed across the three aetiological groups of haematuria studied in this report. All of the patients with spontaneous and traumatic haematuria were severe haemophiliacs, a finding that is consistent with previous studies [2,12]. However, severe and nonsevere haemophiliacs were equally represented among our patients with schistosomal haematuria, a finding that suggests that severity of haemophilia have no effect on host susceptibility to schistosomiasis. The major risk factors for acquiring schistosomiasis include exposures to polluted waters for recreational, occupational or domestic utilization [5]. Haemophiliacs in the tropics are poorly treated and are often physically incapacitated by musculo-skeletal

Table 2: Distribution of haemophilia severity within aetiological groups of haematuria among 45 haemophilia patients with haematuria

\begin{tabular}{|c|c|c|c|}
\hline Aetiology of haematuria & $\begin{array}{l}\text { Spontaneous } \\
(n=23)\end{array}$ & $\begin{array}{l}\text { Trauma } \\
(n=14)\end{array}$ & $\begin{array}{l}\text { Schistosomiasis } \\
(n=8)\end{array}$ \\
\hline No. (\%) of patients with severe haemophilia & $23(100)$ & $14(100)$ & $4(50)$ \\
\hline No. (\%) of patients with moderate haemophilia & $0(0)$ & $0(0)$ & $3(37.5)$ \\
\hline No. (\%) of patients with mild haemophilia & $0(0)$ & $0(0)$ & 1 (12.5) \\
\hline Total no. (\%) of patients studied & $23(100)$ & $14(100)$ & $8(100)$ \\
\hline
\end{tabular}


morbidities, which will restrain them from partaking in many of the high-risk activities for acquiring schistosomiasis. This may be the explanation for the relatively low frequency of schistosomiasis of $17.8 \%$ seen among our patients in this study. Nonetheless, parents of haemophilia patients living in schistosomiasis endemic countries should be counseled on how to protect their children from exposures to infected waters. But this may be a difficult task in poor and rural communities where pipe born water is lacking or inadequate.

This study had also revealed that patients with schistosomal haematuria significantly differ from their counterparts with non-schistosomal haematuria in some haematological parameters including $\mathrm{Hb}$ concentration, haematocrit, eosinophil count and platelet count. The $\mathrm{Hb}$ concentrations among our patients with spontaneous and traumatic haematuria were only mildly affected, a finding that is in keeping with previous studies, which showed that such types of haematuria were generally mild and did not usually cause significant anaemia [2,12]. In contrast, our patients with schistosomal haematuria had moderately severe depression of their $\mathrm{Hb}$ concentrations. These finding suggest that patients with schistosomal haematuria had severe haematuria and severe anaemia. This would imply that patients with schistosomal haematuria were more likely to require transfusion of blood or blood products with attendant risks of contracting blood born infections such as hepatitis and HIV. These risks are particularly high in the tropics where the prevalence of blood born infections are high and transfusion safety is low due scarcity or lack of recombinant blood products and viral inactivation techniques, both of which have greatly revolutionised transfusion safety in the developed countries in current times [13]. Patients with schistosomal haematuria had significantly elevated mean platelet count, which is interpreted to be due to reactive thrombocytosis resulting from the combined effect of active vesical inflammation and haemorrhage as well raised erythropoietin levels due to severe anaemia [14]. Eosinophilia was exclusively seen in patients with schistosomal haematuria in whom it occurred in the majority of cases and is interpreted to be an expected host response to the S. haematobium parasite [15]. The overall haematological profile of our patients suggest that urinary schistosomiasis should be strongly suspected in any haemophiliac who lives in the tropics and presents with a triad of severe haematuria, significant anaemia and eosinophilia.

The severity of haematuria in our patients with schistosomiasis is thought to be due to a compounded pro-haemorrhagic interaction between the parasite and the host. Firstly, because of their haemostatic abnormality, the haemophilic host infected by S. haematobium is more likely to have severe haematuria from the inflamed, ulcerated and hyperaemic vesical epithelium. Secondly, S. haematobium parasite is known to secrete serine protease inhibitors with anti-thrombin properties that would synergistically interact with the haemostatic abnormality of the haemophilic host, a situation that would further escalate the severity of the haematuria [16]. We believe that this superimposed prohaemorrhagic host-parasite relationship is the explanation for the particularly severe haematuria seen in haemophilia patients with urinary schistosomiasis.

Urinary schistosomiasis has a therapeutically significant implication on the management and prognosis of haematuria in the haemophilic patients. This is because while spontaneous and traumatic haematuria may remit spontaneous with bed rest or after giving factor replacement therapy $[4,12]$, haematuria due to urinary schistosomiasis would not remit unless definitive chemotherapy with anti-schistosomal drugs are administered. It is therefore imperative that all cases of haematuria seen among haemophilia patients living in tropical countries where urinary schistosomiasis is endemic should be properly investigated by urinalysis for early detection and treatment.

It must be appreciated that schistosomiasis is a major

\section{Table 3: Mean ages and values of haematological parameters with respect to aetiological groups of haematuria among 45 haemophilia patients with haematuria}

\begin{tabular}{|c|c|c|c|}
\hline Aetiology of haematuria & $\begin{array}{l}\text { Sponta- } \\
\text { neous } \\
(n=23)\end{array}$ & $\begin{array}{l}\text { Trauma } \\
(n=14)\end{array}$ & $\begin{array}{l}\text { Schistosomiasis } \\
(n=8)\end{array}$ \\
\hline $\begin{array}{l}\text { Age (years) } \\
(\text { mean + SD) }\end{array}$ & $9.8+1.5$ & $\begin{array}{l}9.5+ \\
1.5\end{array}$ & $10.3+2.1$ \\
\hline $\begin{array}{l}\mathrm{Hb}(\mathrm{g} / \mathrm{dL}) \\
(\text { mean }+\mathrm{SD})\end{array}$ & $11+1.2$ & $\begin{array}{l}11.5 \\
+1.2\end{array}$ & $8.5+1.1$ \\
\hline $\begin{array}{l}\text { Haematocrit (l/l) } \\
\text { (mean + SD) }\end{array}$ & $0.33+0.02$ & $\begin{array}{l}0.34+ \\
0.03\end{array}$ & $0.25+0.03$ \\
\hline $\begin{array}{l}\text { TLC count }\left(\times 10^{9} / L\right) \\
(\text { mean }+S D)\end{array}$ & $8.24 \pm 1.1$ & $\begin{array}{l}7.84 \pm \\
1.3\end{array}$ & $8.53 \pm 1.5$ \\
\hline $\begin{array}{l}\text { Neutrophil count } \\
\left(\times 10^{9} / \mathrm{L}\right) \\
(\text { mean }+\mathrm{SD})\end{array}$ & $4.6 \pm 1.3$ & $\begin{array}{l}4.3 \pm \\
1.2\end{array}$ & $4.5 \pm 0.7$ \\
\hline $\begin{array}{l}\text { Lymphocyte count } \\
\left(\times 10^{9} / \mathrm{L}\right) \\
(\text { mean }+\mathrm{SD})\end{array}$ & $3 \pm 0.3$ & $\begin{array}{l}3 \pm \\
0.25\end{array}$ & $3.2 \pm 0.26$ \\
\hline $\begin{array}{l}\text { Monocyte count } \\
\left(\times 10^{9} / \mathrm{L}\right) \\
(\text { mean + SD) }\end{array}$ & $0.4 \pm 0.1$ & $\begin{array}{l}0.3 \pm \\
0.12\end{array}$ & $0.4 \pm 0.11$ \\
\hline $\begin{array}{l}\text { Eosinophil count } \\
\left(\times 10^{9} / \mathrm{L}\right) \\
(\text { mean }+\mathrm{SD})\end{array}$ & $0.21 \pm 0.07$ & $\begin{array}{l}0.2 \pm \\
0.06\end{array}$ & $0.42 \pm 0.07$ \\
\hline $\begin{array}{l}\text { Number (\%) of patients } \\
\text { with eosinophilia }\end{array}$ & $0(0)$ & $0(0)$ & $6(75)$ \\
\hline $\begin{array}{l}\text { Basophil count }\left(\times 10^{9} / \mathrm{L}\right) \\
(\text { mean }+\mathrm{SD})\end{array}$ & $\begin{array}{l}0.03 \pm \\
0.008\end{array}$ & $\begin{array}{l}0.04 \pm \\
0.01\end{array}$ & $0.03 \pm 0.01$ \\
\hline $\begin{array}{l}\text { Platelet count }\left(\times 10^{9} / \mathrm{L}\right) \\
(\text { mean } \pm \mathrm{SD})\end{array}$ & $226 \pm 27$ & $\begin{array}{l}237 \pm \\
30\end{array}$ & $466 \pm 37$ \\
\hline
\end{tabular}

Hb: Haemoglobin; TLC: total leucocyte count; eosinophilia: eosinophil count $>0.45 \times 109 / /$ 
cause of iron deficiency even in haemostatically normal hosts [17]. We therefore believe that the superimposed pro-haemorrhagic host-parasite relationship, as earlier mentioned, would make the haemophiliac host to be at greater risk of iron deficiency. The clinical implication of iron deficiency in the haemophilic child goes beyond its physical consequences such as anaemia and growth retardation. In addition, iron deficiency is also associated with cognitive impairment and poor intellectual attainment in school [18]. These are undesirable for the haemophiliac children in whom optimal intellectual attainment is essential in order to enable them secure well-remunerated 'white collar' jobs that would help them offset the medical cost of their disease when they reach adult hood. This is imperative in tropical countries where social security and health insurance cover are virtually non-existent. Low intellectual attainment would generally lead to 'blue collar' jobs, which are unsuitable for the haemophiliac because such jobs are generally associated with greater physical labour, increased likelihood of bodily injuries and high risks of accidental bleeding, all of which are contrary to healthy living for the sufferers of haemophilia even in its mildest form.

\section{Conclusion}

Urinary schistosomiasis is an important cause of haematuria in northern Nigerian haemophiliacs in whom it is responsible for $17.8 \%$ of the cases of haematuria. Schistosomal haematuria was severe and caused significant anaemia in contradistinction to spontaneous and traumatic haematuria that were mild and did not cause significant anaemia. A bilaterally pro-haemorrhagic host-parasite relationship was thought to be responsible for the severe haematuria seen in haemophilia patients with schistosomiasis, a situation that would increase their risk of iron deficiency and its attendant consequences including childhood cognitive impairment. All cases of haematuria in haemophiliacs living in countries where schistosomiasis is endemic should be properly investigated by urinalysis for early detection and treatment. Any haemophiliac who lives in the tropics and presents with a triad of severe haematuria, significant anaemia and eosinophilia should evoke the strongest clinical suspicion for schistosomiasis. Parents of haemophilia patients should be counseled on how to protect their children from exposures to infected waters.

\section{Conflict of Interest}

None of the authors have any conflict of interest in this publication.

This is an Open Access article distributed under the terms of the Creative Commons Attribution License (http://creativecommons.org/licenses/ by/2.0), which permits unrestricted use, distribution, and reproduction in any medium, provided the original work is properly cited.

\section{References}

1. Tantawy AAG. Molecular genetics of hemophilia-A: Clinical perspectives. Egypt J Med Hum Genet 2010; 11: 105-114. doi:10.1016/j. ejmhg.2010.10.005.

2. Benedik-Dolničar M. Haematuria in patients with haemophilia. Zdrav Vestn 2008; 77: 117-120. http://vestnik.szd.si/index.php/ZdravVest/article/ view/897/776.

3. Ghosh K, Jijina F, Mohanty D. Haematuria and urolithiasis in patients with haemophilia. Eur J Haematol 2003; 70: 410-412.

4. Quon DV, Konkle BA. How we treat: Haematuria in adults with haemophilia. Haemophilia 2010; 16: 683-685. doi: 10.1111/j.13652516.2009.02171.x.

5. World Health Organization. Schistosomiasis Fact Sheet No. 115, Geneva, updated May 2015. Available from http://www.who.int/mediacentre/ factsheets/fs115/en/ (Accessed 7 December 2015).

6. Ahmed SG, Kagu MB, Ibrahim UA. Impact of urinary schistosomiasis on haematological parameters and frequency of vaso-occlusive crisis among patients with sickle cell disease in northern Nigeria. Egypt $\mathrm{J}$ Haematol 2014; 39: 58-63. doi:10.4103/1110-1067.139762.

7. Biu AA, Kolo HB, Agbadu ET. Prevalence of Schistosoma haematobium infection in school aged children of Konduga Local Government Area, Northeastern Nigeria. Int J Biomed Health Sci 2009; 5: 181-184. http:// www.asopah.org/journals/ijbhs/ijbhs5/ijbhs540509121.pdf.

8. Ugbomoiko US, Ofoezie IE, Okoye IC, Heukelbach J. Factors associated with urinary schistosomiasis in two peri-urban communities in southwestern Nigeria. Ann Trop Med Parasitol 2010; 104: 409-419. doi: 10.1179 /136485910X12743554760469.

9. Adesola AT, Akibu OO, Ademola OG, Akinwale A. Haematuria in rural primary school children in south western Nigeria-Using Combi Test Strips. Res J Med Sci 2008; 2: 287-290. http://medwelljournals.com/ abstract/?doi=rjmsci.2008.287.290.

10. Laffan M, Manning R. Investigation of haemostasis. In: Lewis SM, Bain BJ, Bates I, eds. Practical Haematology, 10th edn. London, Churchill Livingstone; 2006: 379-440.

11. Cheesbrough M. Examination of urine. In: Cheesbrough M, ed. District Laboratory Practice in Tropical Countries, 2nd edn. Delhi, Cambridge University Press; 2006: 105-115

12. Chakarova P, Šukarova E, Chakarov R, et al. Renal changes in haemophilia-A. Trakia J Sci 2005; 3: 52-55.

13. Lee CA. Blood borne infections and haemophilia: the worst of times. J Haem Pract 2015; 2: 5-7. doi: 10.17225/jhp00049.

14. Kaushansky K. Reactive thrombocytosis. In: Kaushansky K, Lichtman M, Beutler E, Kipps TJ, Seligsohn U, Prchal J, eds. Williams Hematology, 8th edn. New York, McGraw-Hill; 2010: 1929-1932.

15. Wardlaw AJ. Eosinophils and their disorders. In: Kaushansky K, Lichtman M, Beutler E, Kipps TJ, Seligsohn U, Prchal J, eds. Williams Hematology, 8th edn. New York, McGraw-Hill; 2010: 897-913.

16. Mebius MM, van Genderen PJJ, Urbanus RT, et al. Interference with the host haemostatic system by schistosomes. PLoS Pathog 2013; 9(12): e1003781. doi: 10.1371/journal.ppat.1003781.

17. Friedman JF, Kanzaria HK, McGarvey ST. Human schistosomiasis and anemia: the relationship and potential mechanisms. Trends Parasitol 2005; 21: 386-392.

18. Jáuregui-Lobera I. Iron deficiency and cognitive functions. Neuropsychiatr Dis Treat 2014; 10: 2087-2095. doi: 10.2147/NDT.S72491. 